\title{
Fusion of Multiple Intelligences for Developing Natural Interaction in the ESL Classroom
}

\author{
P. Bhaskaran Nair \\ Professor of English
}

Hindustan (Deemed to be) University

Padur, Chennai, India

bhaskaranpnair@yahoo.co.in

nairpbhaskaran@gmail.com

\section{Abstract}

ESL teachers are caught between two diverging socio-psychological modes of existence. On the one side, the inherent artificiality of teaching-learning a second or foreign language in a formal classroom forces them to helplessly look for meaningful activities in the class, so that learners can be motivated and get engaged in the processes of socializing the target language. On the other side, the administrative compulsions and the parental pressure force them to forget 'the learner' and focus on 'teaching'. In unguarded moments, any average ESL teacher may reflect on the past classroom performances of years and may feel dissatisfied. This paper tries to make use of the pedagogic construct of teacher intervention following the guidelines offered by Howard Gardner's theory of Multiple Intelligences and Abraham Maslow's psychological theory of the need of self- actualization. As part of an informal longitudinal study, the researcher has tried to explore the rich resources of the first language in enhancing second language communication skills. 
Keywords and phrases: Self-actualization, Multiple Intelligences, Behaviourism, Cognitivism, Scaffolding.

The Harvard psychologist Howard Gardner's (1983) theoretical postulation of multiple intelligences created long-lasting ripples in educational psychology. Gardner questioned the traditional theory of treating intelligence as a single entity, that it results from a single factor, and that it can be measured simply via IQ tests. His suggestion for including more intelligences, functioning parallel to the conventionally recognizes verbal, logical and mathematical combination was appealing to many in the field of psychology and education, though Gardner himself was sceptic about categorizing students according to the eight or nine (two were added later) intelligences (Gardner, 2013).

Though not fully empirically validated (Sternberg, 1993) and though much challenged by consequent research (Traub,1998; Ploeg, 2016), Gardner's theory remains much favoured by educationists (Howard-Jones,2010). One may rightly remark: You may agree or disagree with Gardner; but you can't ignore him. He has been, in Smith and Smith's (1994) terms, 'a paradigm shifter'.

According to Gardner, intelligence is "a bio-psychological potential to process information that can be activated in a cultural setting to solve problems or create products that are of value in a culture (Gardner,1999: 33-34). It may remain a mystery in some sense why the definition and scope provided by the behaviourist school of psychology to such an important concept like intelligence didn't undergo much change over decades, even though cognitivism had started dominating the field by the mid- $20^{\text {th }}$ century. Gardner himself expresses this concern in 1993 in the tenth anniversary edition of the volume Frames of Mind: The theory of multiple intelligences.

In the heyday of the psychometric and behaviorist eras, it was generally believed that intelligence was a single entity that was inherited; and that human beings - initially a blank 
slate - could be trained to learn anything, provided that it was presented in an appropriate way. Nowadays an increasing number of researchers believe precisely the opposite; that there exists a multitude of intelligences, quite independent of each other; that each intelligence has its own strengths and constraints; that the mind is far from unencumbered at birth; and that it is unexpectedly difficult to teach things that go against early 'naive' theories of that challenge the natural lines of force within an intelligence and its matching domains. (Gardner, 1993: xxiii).

Motivated and inspired by great souls such as Eric Erickson, David Riesman and Jerome Bruner while at Harvard, Gardner started studying human mind making by making use of the resources so far available, and also started thinking in new directions. His intensive analysis of human intelligence for more than two decades led to the conclusion of replacing the notion of human intelligence as a 'single entity' with a broader spectrum of 'multiple intelligences' which function in collaboration and correlation. Gardner realized the inadequacy of the construct of the single-faceted intelligence in understanding the whole range of human intelligence and therefore provided a matrix of seven intelligences (to which later two more were -one each after two intervals). Thus, the present matrix which is currently in use, especially for educational purposes consists of Linguistic, Logicalmathematical, Musical, Bodily-kinaesthetic, Spatial, Interpersonal, Intra-personal, Naturalistic and Existential intelligences.

Since the scope of this paper has been limited to making use of the theory of multiple intelligences in a second language classroom, a detailed discussion of the prerequisites for each candidature may not be relevant here. The experimental study tries to explore the hidden potentials of varying intelligences present in varying degrees, latent or dormant in each student for enhancing second language learning. Gardner has stated that these intelligences hardly exist in isolation or function independently. Therefore, the research question this paper 
poses is that why the potentials of other intelligences can't be explored for furthering linguistic intelligence.

Though second language learning falls under the category of linguistic intelligence, it has been proved that there is a marked difference between natural language acquisition and the way a second language is learnt through formal instruction. It has been proved that the more support or scaffolding SL instruction can draw from external agencies such as adultpeer interaction (Vygotsky,1978; Bruner, 1978), the better will be the learning outcome. The study hypothesizes that if there are one's own inner potentials existing in the form of multiple intelligences, which can be made to function as scaffolding agencies in second language learning, such efforts are likely to result in more enhanced outcome than outside scaffolding can offer.

One may ask - why and how multiple intelligences can be fused with the 'original' intelligence? At the outset, let us remind ourselves that the ultimate objective of any human behaviour is self- actualization, so much so with learning objectives, as well. The quest "who am I?' and the search of its answer, 'what can I perform' together lead one to the stage of self-actualization. In Abraham Maslow's (1943) pyramid of human needs, self-actualization is on the top. This stage refers to a person's potential, self-fulfilment, and peak experiences. It is a stage of desire person. In some, the need may be expressed academically, artistically or athletically. In some others, it may be a desire to express oneself through creativitydrawing, painting, photography, music and so on.

In an ESL class, the teacher is situated in a gap: on the one side, there are certain skills and competencies the learners are expected to master by the end of a fixed time limit. To meet this end, instructional materials are there, suggested or prescribed methodologies are there, recommended transactional strategies are there. Still, she faces difficulty in reaching the target point. 
On the other side, the learners have come to school with immense potentials which are not there in the teacher's list of objectives, nor in the syllabus, either. But, a rather-wellinformed teacher can bridge this gap if she is well aware of the pedagogic notion of teacher intervention as a tool to enhance learning outcome, and the psychological theories of Maslow's self-actualization and Gardner's multiple intelligences.

The study, which is reported below briefly, makes use of mainly musical, interpersonal, kinaesthetic, naturalistic intelligences in promoting linguistic intelligence. In this experiment, second language learning simultaneously gets embedded in multiple intelligences and gets extended to them, as well.

The study was conducted as a part of the Rural Empowerment through English Language Education Programme (REELEP), organized by a registered NGO of English teachers, in Kerala. English Language Teachers' Interaction Forum (ELTIF) has been organizing various programmes for enhancing English language education in rural and tribal areas. They include communicative English courses for learners, self-empowerment programmes for teachers, awareness programmes for parents and public, support programmes for the young mothers of school children, women empowerment programmes and so on. The programmes organized with the local support during weekends and holidays (including summer vacation) attract in large numbers, all the stakeholders of English language learning mentioned above. Communicative English courses for children used to have parents at the back of the class, as observers so that back at home, those educated parents can help their children with the help of the novel and interesting activities practised in the class.

Diversity seems to be the essence of beauty. Diverse artistic talents, while fused together, are likely to give birth to new beauties. At least, says so the result of a classroom experiment. One may ask, "What is the relevance of diverse artistic talents in an English class? You teach grammar and vocabulary, take care of reading comprehension, give some 
writing assignments, and if you are very particular, do some role-play activities so that spoken English too is "well taken care of."

Well, I'm not asking anybody to give up grammar, reading or writing — all of them must stay. But, to have a little noise in an English class (where only the teacher" voice is heard), a new activity has been suggested. You just take it as fun.

Let's begin with a film song-yes, in the mother tongue. A very popular one with excellent lyrical beauty, wonderfully composed, tuned and sung. "Who is going to sing this song?" Many raise their hands.

Before they sing the song, ask the class that each should note down two or three phrases of their choice while listening. After the song, each should select one phrase/word and first translate it into English, and then perform an action related to that word/phrase. The 'action' can be a real action (dancing, whistling, humming...), miming (gardening, watering, cooking...), illustrating verbally ("Last night I had a dream. I saw an elephant in my dream"- -based on the word dream in the film song), drawing (a tree), origami (a paper plane-since the word chosen from the song is aeroplane), telling a very brief story (based on a phrase in the song), doing a mono-act(based on an emotion depicted in the song), narrating an event - imaginary or real, writing a dialogue between the characters mentioned in the song - two lovers, acting along with a short dialogue, composing two or three lines of a poem. Working in pairs or small groups, a few of them can translate the poem in meaningful units—couplets, stanzas, refrain etc.

Once they listened to the song, selected a few words or phrases, and finally picked one from the list, what each has to do is as follows:

Tell the class what the word/phrase selected from the song is: "I have selected the word '......' (the original). In English, it means flutist. I am going to act like that flutist in the song". Now, the student performs /mimes for one or two minutes. 
Another student: "I have selected the phrase, '......', which means 'thick forest'. Now, look at my drawing. How is my forest?"(Shows the picture.)

Yet another student: "I have also taken the same phrase, 'thick forest'. Now, let me walk lonely along the thick forest" (Mimes).

Another student: "The phrase I have chosen is '....'. It means very sad and lonely. I have written two lines of a poem, of course, in our mother tongue/English. Let me read." (Reads.)

The students may not be able follow the instructions clearly in the beginning. What the teacher has to do is to choose two or three words/phrases on behalf of each student. Then, depending on their talents ask them to pick one. Then, provide models. For acting, miming, dancing, drawing etc. they don't need models. They may do on their own, once they understood the instructions. For writing a dialogue, composing two lines of a poem, telling a story, narrating an event etc. they might need models to begin with. The teacher is expected to provide models.

On a closer look, one can see that quite a few paradoxes have been brought to reconciliation through this fusion. The unfelt need of learning a foreign language versus the natural instinct of singing film songs, the usual monotony of the English class versus the diversity of the fusion of various artistic talents, the traditional teacher-dominated class versus the self-motivated learner engagement, book-based language learning versus language being employed for self-actualization, passivity of the learner versus learner-initiated follow up activities, individualized learning versus collaborative learning, learning the rules (usage) first and later trying to use them versus learning the language by using it - these are some of the 'mismatches' which have been brought together, that too quite naturally. 


\section{References}

Bruner, J. S. (1978). The role of dialogue in language acquisition. In A. Sinclair, R., J. Jarvelle, and W. J.M. Levelt (eds.) The Child's Concept of Language. New York: Springer-Verlag

Gardner, H (1983; 1993) Frames of Mind: The theory of multiple intelligences, New York:Basic Books.

Gardner, H (1999), Intelligence Reframed: Multiple Intelligences for the 21st Century, Basic Books

Gardner, H (2013). 'Multiple intelligences' are not 'learning styles' The Washington Post Howard-Jones, Paul (2010), Introducing Neuroeducational Research, Taylor \& Francis Maslow, A. H. (1943). A Theory of human Motivation. Psychological Motivation, 50.4. pp.370-396.

Maslow, A. H.(1962). Toward a Psychology of being. Princeton, D. Van Nostrand Company.

Smith, L. G. and Smith, J. K. (1994) Lives in Education. A narrative of people and ideas 2e, New York: St Martin's Press.

Sternberg, R. J. (1983). "How much Gall is too much gall? Review of Frames of

Mind: The theory of multiple intelligences". Contemporary Education Review. 2 (3): 215224.

Traub, J. (1998). "Multiple intelligence disorder". The New Republic. 219 (17): 20.

Van der Ploeg,( 2016) Multiple Intelligences and pseudo-science . academia.edu

Wood, D; Bruner, J.S; and Ross.G. (19760. The role of tutoring in problem solving.. Journal of Child Psychology and Psychiatry. 17: 89 - 100.

Vygotsky, L.S. (1978). Mind in Society. Cambridge, Mass. MIT Press. 